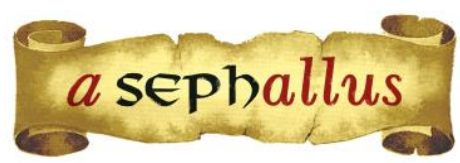

Revista aSEPHallus de Orientação Lacaniana

Núcleo Sephora de Pesquisa sobre o Moderno e o Contemporâneo

ISSN $1809-709$ X

\title{
Uma Conversação com os melhores alunos: do sintoma como funcionamento ao mais além da segregação
}

\section{Bruna Simões de Albuquerque}

Orcid: https://orcid.org/0000-0002-0776-6960

Doutora pela Faculdade de Educação da Universidade Federal de Minas Gerais /UFMG (Minas Gerais, Brasil)

Mestre em Psicopatologia e Estudos Psicanalíticos pela Université Strasbourg (Strasbourg, França)

Membro do Núcleo de Pesquisa em Psicanálise e Educação (NIPSE) da Faculdade de Educação da

Universidade Federal de Minas Gerais / UFMG (Minas Gerais, Brasil)

Membro do Grupo de Pesquisa Brota - Juventude, Educação e Cultura do CNPq

Correspondente Internacional da Federação Européia de Psicanálise e Escola Psicanalítica de Strasbourg

(FEDEPSY) (Strasbourg, França)

E-mail: brualbuquerque@gmail.com

Lisley Braun

Orcid: https://orcid.org/0000-0002-7799-3421

Doutora em Psicologia - Estudos Psicanalíticos pela Universidade Federal de Minas Gerais / UFMG (Minas

Gerais, Brasil)

Mestre em Promoção da Saúde e Prevencaao da Violência na Faculdade de Medicina da Universidade Federal de Minas Gerais / UFMG (Minas Gerais, Brasil)

Especialista em Teoria Psicanalítica pela Faculdade de Filosofia e Ciências Humanas da Universidade Federal de Minas Gerais / UFMG (Minas Gerais, Brasil)

Graduada em Psicologia pela Universidade Federal do Espírito Santo / UFES (Espírito Santo, Brasil)

E-mail: lisley@gmail.com

Ana Lydia Bezerra Santiago

Orcid: https://orcid.org/0000-0003-4405-6244

Pós-doutora em Teoria Psicanalítica pela Universidade Federal do Rio de Janeiro / UFRJ (Rio de Janeiro, Brasil) e pelo Departamento de Psicanálise da Université de Paris VIII (Paris, França) Doutora em Psicologia Clínica da Universidade de São Paulo / USP (São Paulo, Brasil)

Professora do Programa de Pós-graduação em Educação da Faculdade de Educação da Universidade Federal de Minas Gerais / UFMG (Minas Gerais, Brasil) Membro da Escola Brasileira de Psicanálise / EBP e da Associação Mundial de Psicanálise /AMP E-mail: analydia.ebp@gmail.com

\begin{abstract}
Resumo: Este artigo apresenta experiência de pesquisa/intervenção realizada com alunos da rede pública por meio da metodologia da Conversação de Orientação Psicanalítica. Encontramos os "melhores" alunos de uma escola e os ruídos em torno dessa nomeação. Por meio desse resto, desse ruído que retorna, atrapalhando o processo de aprendizagem e de convivência, verificamos efeitos de segregação que mantinham os alunos em uma guerra interna. Partimos então da leitura do sintoma como modo de funcionamento na escola e recolhemos os efeitos plurais de segregação que podem produzir destinos mortíferos, com o objetivo de ultrapassar a sensação de generalizada impotência diante do que não funciona. O objetivo é escutar o sintoma para então operar a partir dele.
\end{abstract}

Palavras-chave: psicanálise; educação; conversação; sintoma; segregação

A Conversation with the best students: from the symptom as a way to function to something beyond segregation: This article presents an experience of research-intervention carried out with public school students through the Psychoanalytical Orientation Conversation methodology. We found the "best" students at a school and the noises in the school community surrounding such an appointment. Through this remain, this noise that returns, disrupting the learning and the coexistence process, we verified segregation 
effects that kept the students in an internal war. We begin from reading the symptom as a way of functioning in school and collect the plural effects of segregation that can produce deadly fates, in order to overcome the feeling of generalized impotence in the face of what is dysfunctional. The purpose is to listen to the symptom and then operate from it.

Keywords: Psychoanalysis; education; conversation; symptom; segregation.

Une conversation avec les meilleurs élèves: du symptôme comme mode de fonctionnement à un au-delà de la ségrégation: Cet article présente une expérience de recherche-intervention menée auprès d'élèves des écoles publiques à travers la méthodologie "Conversation d'Orientation Psychanalytique". Nous avons rencontré les «meilleurs» élèves d'une école et les bruits entourant cette nomination. À travers de l'analyse de ce bruit, ce reste qui revient, perturbant le processus d'apprentissage et de coexistence, nous avons vérifié les effets de ségrégation qui maintenaient les élèves dans une guerre interne. Nous partons d'une lecture du symptôme comme un mode de fonctionnement à l'école et nous recueillons les effets divers de la ségrégation qui peuvent produire des destins mortels, dans le but de surmonter le sentiment d'impuissance généralisée face à ce qui est dysfonctionnel. Le but est d'écouter le symptôme pour opérer à partir de lui.

Mots clés: psychanalyse; éducation; conversation; symptôme; ségrégation 


\section{Uma Conversação com os melhores alunos: do sintoma como funcionamento ao mais além da segregação}

Bruna Simões de Albuquerque \& Lisley Braun \& Ana Lydia Santiago

\section{Introdução}

O sintoma refere-se à relação do sujeito com o Outro, a seu modo de fala e aos seus modos de arranjo na vida. Os sintomas, os sonhos e os atos falhos são formações do inconsciente que apenas adquirem valor por meio das explicações do sujeito (Lacan, 1975/1998). O inconsciente é a maneira de o sujeito estar impregnado pela linguagem, e isso não se dá sem relação ao modo como foi desejado (Lacan, 1975/1998). Assim, estar impregnado pela linguagem remete diretamente ao modo de falar que foi instilado pelos pais e reverbera sobre as formações do inconsciente, entre elas, o sintoma. Afirmamos, então, com base em Lacan (1975/1998), que o sintoma tem relação direta com o modo como o sujeito foi impregnado pela linguagem e com a maneira como constituiu seu modo de fala de acordo com o desejo do Outro. O sintoma como o modo que cada um encontrou de se sustentar em relação à linguagem. Lacan (1975/1998) explicita que é pelo modo como lalíngua foi falada e ouvida por cada um que ela reaparecerá nas falhas da linguagem, nos sonhos, nos tropeços, enfim, infiltrada e irrompendo nos modos particulares de dizer.

Lacan (1975/1998) retoma a concepção freudiana de sintoma para dizer que os sintomas têm um sentido e apenas são interpretáveis corretamente considerando as primeiras experiências do paciente constitutivas de sua realidade sexual. Essa realidade sexual existe justamente em razão da não existência da relação sexual entre o homem e a mulher (Lacan, 1975/1998). É apenas diante de uma interpretação que considere tudo isso que o sujeito poderá abrir mão e deixar cair um pedaço de seu sintoma.

Podemos considerar, então, o sintoma como o modo próprio de responder à realidade e ao que ela apresenta ao sujeito, um modo de funcionar frente à realidade e à sexualidade. Para os seres que falam, o sintoma pode ser tomado como o que não cessa de se escrever, tributário da existência de um real bem particular e do fato de não haver inscrição no real de um saber relativo à sexualidade (Miller, 2000). Não está previamente escrito como gozar ou como encontrar um parceiro, tarefas que, como veremos, impõem-se a cada ser falante e, de modo mais radical, ao adolescente diante da puberdade. Aquilo que condiciona o modo como cada um vai lidar com a sua sexualidade não está explícito de antemão, o que faz com que o impacto do trauma do gozo sexual e da não existência da relação sexual se faça sentir sempre no um a um. Miller (2000) explica a relação entre o impossível (não cessa de não se escrever), o necessário (não cessa de se escrever), que é o sintoma, e o contingente (cessa de não se escrever) que remete ao encontro com o gozo e com o Outro (nesse caso o amor). É pela via do sintoma que se ama e que se goza. 
Nossa tendência espontânea é considerar o sintoma como uma disfunção. Dizemos sintoma quando algo claudica, porém a disfunção sintomática só se localiza em relação ao Ideal. Quando cessamos de localizá-la em relação ao Ideal, ela vira funcionamento. A disfunção é um funcionamento, é assim que as coisas funcionam. (Miller, 2000, p. 174).

O sintoma diz respeito à constituição de um modo de funcionar que remete tanto à pulsão, ao gozo, quanto à dimensão do Outro. $\mathrm{O}$ sintoma como funcionamento questiona o ideal coletivo $\mathrm{e}$ abre espaço para a parte de gozo que diz respeito a cada um (Santiago, 2008). A ideia do sintoma é a de que ele produz um acordo entre matérias irreconciliáveis, constituindo um modo próprio para lidar com o trauma da linguagem e da relação com o corpo e com o Outro. Habitualmente, o sintoma é considerado uma patologia a ser curada, diante da perspectiva aqui apresentada, passa a ser tomado como um modo de funcionamento e remete ao fato de o significante ter uma incidência de gozo sobre o corpo, ou seja, o sintoma como a inscrição de uma relação entre o significante e o gozo (Miller, 2015). Para Miller (2000), o sintoma como funcionamento pode ser tanto social quanto individual e, nos dois casos, são modos de envolver e situar o mais-de-gozar. Do ponto de vista social, são modos de funcionar, de gozar, oferecidos pela cultura, ou seja, modos de satisfazer a pulsão pelos semblantes que, quando não bastam, dão lugar aos sintomas individuais (Miller, 2000). Assim, diante da ausência de prescrição, o sintoma é considerado pelo autor como um modo de funcionar, individual ou socialmente, para saber o que fazer com o outro sexo. Tomaremos a escola como um território no qual o social e o individual se superpõem para investigar como fazer uma leitura do sintoma como funcionamento?

Na perspectiva do sintoma que nos orienta, entendemos igualmente que é o próprio sujeito que pode dizer alguma coisa sobre o mal-estar por ele experimentado ou por aquilo que simplesmente não vai bem. É o sujeito que tem o que dizer sobre sua dificuldade. Interessa-nos tomar como ponto de partida justamente a queixa, ou seja, aquilo que escapa ou que resiste ao que está previsto nas instituições e que perturba, produzindo pontos de opacidade e de paralisia das ações, mas que, principalmente, explicita um modo próprio de funcionamento.

No contexto de nossas pesquisas ${ }^{1}$ na interface com o campo da educação, tomamos "algo que não vai bem" e que impossibilita a transmissão como um sintoma, ou seja, algo que insiste em se inscrever e que resiste ao discurso pedagógico. Verificamos que há sintoma quando o recurso aos protocolos e às normas não é suficiente, algo escapa às tentativas de solução e às explicações dadas pelos discursos universais que fundam os programas governamentais (Santiago, 2017). Cada sintoma de uma instituição escolar representa um índice das possíveis formas de expressão do real impossível e dos limites da própria educação (Santiago, 2011). Como consequência da introdução do discurso da ciência na escola, verificamos a crescente produção da patologização e medicalização de seus impasses. Os alunos considerados em fracasso escolar são classificados no lado do déficit, marcados por uma nomeação que abafa a possibilidade de uma interrogação e de 
uma escuta a respeito do processo enfrentado (Santiago, 2011).

Para avaliar as diversas manifestações do sintoma de fracasso na atividade escolar, é fundamental incluir a dimensão pulsional (Santiago, 2005). Essa premissa é que vai possibilitar tomar a criança, o adolescente e o adulto como sujeitos e não como objetos de uma transmissão objetiva ou, se tal processo falha, de um diagnóstico. O sintoma como campo para uma escuta diz respeito à relação muito particular de cada sujeito com o saber, e não às manifestações que possibilitarão um diagnóstico fechado. Ou, seja, dá lugar ao modo de gozo de cada um, que não é apreensível pelo nome de uma patologia.

Nesse sentido, o diagnóstico freudiano permite postular o fracasso como signo do que não cessa de não se escrever na vida desses sujeitos. A tarefa do discurso analítico, diante disso, consiste em tentar fazer desse impossível um sintoma, para além das determinações orgânicas ou cognitivas imputadas pelo discurso da ciência como fonte de déficit do sujeito. (Santiago, 2005, p. 20).

Encontramos, então, duas vias para considerar a questão do sintoma no âmbito escolar. $\mathrm{Na}$ primeira, ele aparece como aquele que vai impedir a emergência do particular de cada aluno, tomando-o como um objeto, ou seja, trata-se de uma nomeação do real com base em um significante pertencente ao campo da ciência e que impede a possibilidade de inventar um sintoma próprio (Santiago, 2005). Podemos falar nesse caso em uma tentativa de homogeneização do modo de gozo de cada um de acordo com um ideal de funcionamento, hierarquizando alguns modos como superiores a outros. Esse modo de considerar o sintoma cala o sujeito, pois o impede de tentar dizer algo sobre o mal-estar que experimenta em seu corpo e na relação com o outro. Enfim, sobre o modo que ele encontrou para se virar na vida.

$\mathrm{Na}$ segunda via, o discurso analítico pode operar transformando uma dificuldade em um sintoma. Essa concepção de sintoma pressupõe a produção de um enigma e a eventual possibilidade de endereçamento a um analista com o intuito de decifração. A dimensão do sintoma tal como o consideramos para a atuação nos impasses escolares pressupõe a possibilidade de 0 sujeito tomar a palavra para dizer algo sobre o que não vai bem, ou seja, há a consideração da subjetividade do aluno na leitura de sua relação com o saber e com a aprendizagem. A partir de então, esse sintoma assim acolhido, pode ou não se configurar como um sintoma no sentido analítico do termo, que implica não em um sintoma como determinação de um nome para rotular, mas como a expressão do sexual do inconsciente: "uma desordem que incomoda o sujeito, expressa um conflito psíquico relativo ao sexual do inconsciente e pede interpretação" (Santiago, 2005 , p. 35). Acolher o que vai mal como um sintoma a ser escutado com base nas palavras do próprio sujeito pode ou não se configurar como uma demanda de análise. 
Esse instante da clínica não deixa de evidenciar o papel desempenhado pelo sintoma propriamente analítico, concebido como necessário à deflagração do modo como o sujeito efetua o trabalho de cifração do real do gozo. Resgatar as diferenças que cada sujeito apresenta como efeito desse trabalho não acabaria, certamente, com a segregação escolar, mas possibilitaria, para alguns, a construção do particular do sintoma como um enigma que permite lidar com a pergunta que todo sujeito endereça ao ser, na forma do sentido sexual. (Santiago, 2005, p. 42-43)

Independentemente de um sintoma se configurar ou não como demanda de análise, importa que ele possa fazer enigma, sugerir uma interrogação, para aquilo que não cessa de não se escrever. Assim, a cada vez, cabe a seguinte pergunta: a que serve o modo como se considera um sintoma: calar ou fazer falar o sujeito?

Ao tratarmos do sintoma na escola, pressupomos então a ideia de conflito psíquico e de uma articulação de matérias opostas que encontram aí um acordo, um modo de estarem conectadas. 0 sintoma acaba por operar como resto da articulação entre saber e gozo, podendo ser tomado como causa para novas conexões. Ou seja, um resíduo que, ao ser colocado em movimento pela via da fala, tem a chance de ser reinventado como resposta alternativa ao conflito. No entanto, se o sujeito faz uso de gozo de seu sintoma sem querer saber nada dele e portanto se eximindo cada vez mais do laço social, junto ao reforço dessa dinâmica pela instituição, o sintoma pode paralisar e mortificar o vivo dos encontros na escola. A depender das intervenções realizadas, um sintoma pode se fixar cada vez mais produzindo sofrimento e segregação. Um sintoma tomado no sentido de calar o sujeito, ou seja, no sentido tradicionalmente utilizado, pode produzir nomeações patologizantes e rígidas que oferecem aos alunos identificações engessadas às quais eles podem enganchar seu gozo.

Nessa perspectiva, dar lugar ao sintoma na escola, dizer sim ao modo como cada aluno conciliou para si o irreconciliável da pulsão com a realidade, ajudar o aluno a nomear parte de seu sintoma, pode tirar consistência do uso de gozo solitário que cada um pode fazer do próprio sintoma (Lacadée, 2017).

Encontramos processos de nomeação e identificação que se agravam no ambiente da escola produzindo fracasso escolar, evasão dos alunos e adoecimento dos professores. De um lado, há nomeações impostas para caracterizar os modos de vida dos alunos: modos de falar, de dançar, preferências musicais e de moda, uso de drogas, causas defendidas, posições políticas, comportamentos aparentemente incompreensíveis. Enfim, modos próprios de viver no tempo presente que revelam uma incorporação de traços da época. Esses modos de vida podem suscitar angústia no adulto, que vê aí representados formas contemporâneos do viver que se opõem àqueles de sua geração.

Por outro lado, há nomeações que incidem de acordo com dinâmicas estabelecidas em cada 
escola, ou seja, a escola nomeia parte dos alunos - pode ser uma turma, uma parte dela ou alguns indivíduos - que representam o que há de pior numa dada instituição e que, consequentemente, sofrem segregação. Encontramos, por exemplo, as expressões "resto", "lixo", "favelados", "piores" para nomear algumas turmas, e outras como "os elementos", "o gay", "o burro", "o bandido" para se referir a alguns alunos. Assim se instala a segregação. Dos alunos apenas se espera que façam jus à nomeação que lhes é imposta. E é isso que ocorre. Eles acolhem essas nomeações, identificando-se com o que o Outro the atribui. A escola pode se posicionar como se soubesse de antemão o destino dos alunos, ratificando esse nome de gozo. Identifica-se, por exemplo, o aluno que será um futuro bandido, aquele que não será nada na vida ou outro para o qual a universidade jamais será um caminho possível. Em muitas escolas, tanto da rede pública quando da rede privada, verificamos comumente a prática de separar em turmas diversas os alunos considerados melhores e da mesma forma ocorre com os piores. Impõem-se assim, a partir de uma prática de segregação velada, modos de gozo engessados ao Ideal e ao que não se encaixa nele. Facilmente notamos os efeitos dessa prática que, ao invés de apaziguar a dinâmica escolar com essa pretensa homogeinização, cristaliza nomes do pior culminando em grande parte dos impasses escolares. Do lado dos alunos e dos professores, a falta de respeito, por exemplo, é sempre citada como um dos problemas dentro da sala de aula, que atrapalha a transmissão e que pode ser considerada um dos impasses do próprio processo educativo (Albuquerque, 2019).

Nesse sentido, vemos que a escola é um dos lugares privilegiados para emergir o que incomoda ou que faz questão para os sujeitos. Isso se dá muitas vezes por meio daquilo que agita o corpo tanto das crianças quanto dos jovens, não se encaixando no Ideal escolar. A escola propricia assim certa abundância de conflitos se tomarmos as relações entre alunos e professores, professores e direção, e alunos entre si. É do encontro frequentemente desencontrado entre adultos, crianças e adolescentes que se produz um resto que não cessa de escrever. A resposta mais comum a esse resto que excede e agita os corpos tem sido tentar calá-lo, erradicá-lo, numa tentavia improfícua de tamponar o real da não relação.

Outra resposta possível, longe de se tornar um binarismo, é abrir um campo de escuta para fazer falar o sintoma, e o sujeito. Ou seja, tomar este resto como enigma, dar-lhe valor legítimo de fala, buscar saber mais sobre ele. Nesse artigo apresentamos uma experiência na qual trabalhamos com alunos da rede pública que nos ensinaram sobre os efeitos plurais de segregação que aparecem no ambiente escolar e que são marcados pelo que está em jogo no laço comteporâneo. Encontramos assim os "melhores" alunos de uma escola e os ruídos em torno dessa nomeação. Partimos então desse resto ruído que retorna, atrapalhando o processo de aprendizagem e de convivência. Convidamos os alunos a quererem saber um pouco mais sobre isso que os faz sofrer na escola. Ao realizarmos Conversações ${ }^{2}$ com a turma dos melhores, pudemos verificar efeitos de segregação petrificantes que mantinham os alunos numa espécie de 
guerra interna.

\section{Os melhores: não é fácil ser bom}

Na Conversação diagnóstica a direção da escola em questão apontou a necessidade de um trabalho com algumas turmas consideradas boas, porém questionadoras demais. Ao questionarem os professores, confrontando-os, tais turmas evidenciam aquilo que vai mal na relação professoraluno. É sempre a partir do mal-estar que se delineia para nós o espaço para a intervenção.

Os melhores reclamam da cobrança exaustiva, mas não aceitam quando os professores exigem pouco, ou seja, se queixam que são cobrados e que não o são. Estão sob o imperativo de corresponder à alta expectativa e ao mesmo tempo têm dificuldade de abrir mão disso, alienandose ao lugar que receberam quando colocados todos numa mesma sala, em nome do bom desempenho.

Ao longo das Conversações temos nos deparado com adolescentes saturados pela demanda, anunciada por meio da nomeação e da expectativa do Outro. Em trabalho prévio em outra escola com alunos que, ao contrario das Conversações aqui em questão, eram por sua vez nomeados de "piores", vimos que estes estão saturados por uma expectativa que os direciona ao pior. Por outro lado, os alunos considerados como pertencentes ao grupo dos melhores aqui estudados devem atender a uma expectativa inatingível dos adultos, mas também às suas próprias, a partir desta nomeação. É importante notar que, em ambos os casos, os adolescentes se dizem não escutados e não respeitados pelos adultos.

Os "melhores" alunos deparam-se com a necessidade de crescer e se apresentam sufocados pelas demandas: excesso de matérias na escola, necessidade de conciliar trabalho, estudo, cursos, a preparação para o Exame Nacional do Ensino Médio (ENEM), etc. Além disso, enfrentam dificuldades de convivência com os colegas e na relação com os professores, vivenciando cenas de desrespeito, e mesmo uma "guerra" entre os alunos. Aprendemos com eles que não é fácil ser bom, pois sentem-se punidos por serem os escolhidos, condenados à manutenção do Ideal escolar e social. De acordo com eles, a escola "montou" uma turma com os melhores alunos. Assim, o efeito de segregação dessa montagem se reproduz entre os adolescentes, aparece um desejo de ser, nas palavras deles, "o melhor dos melhores". Vemos que tanto o melhor quanto o pior nomeia, reduz e aprisiona, colando o sujeito à expectativa do Outro. Verificamos com os alunos que, para existirem os melhores, é preciso que outros sejam "rebaixados" ou colocados sob um imperativo de serem melhorados, abrindo mão de sua marca pessoal.

Nesse sentido, nas Conversações, quatro adolescentes se destacam, tanto como porta-vozes do que vai mal na sala, quanto como portadores da diferença que aparece como insuportável aos demais. Eles viviam a curiosa particularidade de terem sido inseridos na turma dos melhores para serem melhorados. Esses alunos, destoantes dos demais, parecem parecem encarnar o que vai mal na turma ao trazerem questões que vão além do desempenho escolar. Suscitam os diferentes 
impasses relativos ao sexo (o gay), à lei (o bandido) e ao saber (o burro). Uma vez na turma dos melhores, tais alunos são considerados excluídos, têm sua marca pessoal associada ao pior e deverão transformá-la para terem a possibilidade de serem incluídos pela via do nome "melhor".

Assim, em uma competição desenfreada entre alunos, alimentada pela escola que estipula e reforça essa nomeação, os melhores vivem em guerra, o que se evidencia na intolerância à diferença, e no receio constante de ser rebaixado pelo colega por sua roupa e suas opiniões. Os adolescentes, ao se identificarem com o nome melhor, devem responder à demanda do Outro com seu saber, não havendo espaço para o que escapa ao saber. Eles se embaraçam com o que não se sabe, e com o que fazer diante do real que emerge. A impossibilidade de tamponar o furo se desenha como fracasso diante da expectativa do Outro. Os adolescentes temem não corresponder mais à posição de outrora, e escutam dos professores que "a turma mudou", ou seja, que a turma não é tão boa quanto antes.

Diante disso, os alunos exigem dos adultos explicações totalizantes e que lhes permitam crescer sem se depararem com o furo no saber. Queixam-se que as aulas são pura "falação" e que às vezes não aprendem "nada". Desse modo, os adolescentes parecem exigir que seus professores também fossem os melhores, que também são obrigados a corresponder às suas expectativas. Num dado momento da Conversação, afirmam que desejam saber o passo a passo da construção de um relatório, pois não suportam arriscar-se no erro, querem realizar as tarefas apenas quando souberem exatamente como fazer, e culpam os professores por não corresponderem nunca a esse ideal de completude da explicação, ou seja, de uma transmissão sem falhas. Parecem não aceitar o fato de que não é possível saber exatamente como se faz um relatório sem tomar o risco ao fazê-lo, na ilusão de postergarem o encontro com o não saber, com o real que faz furo.

Em outro momento, relatam que se articularam contra um professor que "não dava a matéria", que não cobrava. Fizeram greve de silêncio, ou seja, a greve de fala foi a maneira que encontram para se fazerem ouvir. A turma, bastante queixosa, se reconhece como "implicante" e, aos poucos, a partir de nossas intervenções, começou a identificar seus excessos em fazer cumprir essa marca inatingível - o melhor, que sabe tudo, que "tira cem". Refletimos juntamente com os adolescentes sobre como manter uma marca pessoal sem ter como destino a segregação. Ou seja, serem reconhecidos como sujeitos sem precisar abrir mão de serem bons.

Intervimos junto à turma, explicitando que alguns alunos pareciam ser colocados naquela sala dos melhores para serem mellhorados e, como consequência, sua marca pessoal era assolada pelo pior. Perguntamos aos adolescentes se seria possível manter sua marca pessoal, aquilo que nos diferencia como sujeito único, sem ser excluído do grupo e propusemos uma atividade. Os adolescentes concordaram prontamente.

Distribuímos CDs para a turma, dizendo que cada um deveria escrever em uma palavra no CD recebido sua marca pessoal, ou seja, aquilo que cada um acha que é, aquilo que gostaria de ser ou ainda como gostaria de ser no futuro. Quer dizer, alguma coisa do jeito próprio de cada um, 
aquilo que o identifica para o outro. Imediatamente notamos um embaraço em toda a sala! $\mathrm{A}$ princípio os adolescentes consideraram complicado cumprir a tarefa: "uma palavra? Uma palavra só? Pode ser uma abreviação de três palavras?", "que difícil, difícil...". Ao perguntarmos por que estava tão difícil, um aluno responde "Porque é mais fácil falar dos outros". Uma aluna complementa "É muito difícil falar uma coisa de mim para o outro, porque às vezes o outro vai achar diferente". A atividade consistia em um jogo de adivinhação no qual uma dupla de alunos se apresentava e cada um deveria escrever em um papel aquilo que achava que o outro tinha escrito em seu próprio CD. Cada um deveria tentar adivinhar como o outro se representou.

No momento de revelar as respostas, um bonito desencontro apareceu entre aquilo que eu acho que sou ou quero ser e o modo como o outro me vê. Isso teve efeitos na turma, primeiro de risos e surpresa diante do desencontro e depois um efeito de virada. Perceberam, aos poucos, como vinha sendo tratado o insuportável da diferença entre eles. Na primeira dupla, o menino escreve que acha que a colega se representou como "agressiva". Ela tinha marcado em seu cd "estranha", e diz "nuuuu", indagando: "eu sou assim?", surpresa diante da visão do outro. Ela escreve "quieto" enquanto o aluno tinha se representado como "curioso". Houve alvoroço na sala. Na próxima dupla, um dos alunos que mais se sobressai na sala, inteligente e sempre rotulando os colegas, se nomeia "chato", mas foi visto pela colega como "palhaço". A aluna se vê como "perguntadora" enquanto é tomada por ele como "metida". Entre surpresas e risos, os alunos vão dizendo "é difícil, eu não sei o que você pensa", ou ainda, "eu não tenho ideia", "pensei em colocar isso, mas não coloquei". Aquela que se considera "grossa" foi vista pela colega como "comunicativa". Em uma das duplas houve uma coincidência: "nervosa" foi vista como "nervosa". Os alunos se divertem. Ao final da brincadeira a conclusão dada por eles: "Ninguém conhece ninguém". Perguntamos se seria possível guardar sua marca pessoal e estar junto com os outros sem ter de abrir mão daquilo que é próprio de cada um, ao que respondem "a sala fica dividida porque nem todo mundo respeita as marcas do outro".

No último encontro da pesquisa/intervenção os alunos dizem "a gente podia continuar o ano inteiro" e afirmam "resolveu muitos problemas que a gente tinha... passou"; "melhorou a relação na turma, a gente jogou as cartas na mesa, é isso". Nesse momento, vários alunos concordam, dizendo que a Conversação proporcionou uma mudança de posição dos alunos na relação entres eles. Vimos que foi importante para esse grupo poder encontrar a marca pessoal de cada um para além daquilo que os identificava na escola, ou seja, para além da nomeação como os melhores ou escolhidos. A Conversação permitiu a cada um poder se situar enquanto único, a gravar sua marca pessoal que estava apagada sob o imperativo de se tornar mais um entre o grupo.

Entretanto, há pontos que apareceram e que não chegaram a ser trabalhados de modo aprofundado. Se de um lado os encontros possibilitaram aos jovens trabalhar a relação entre pares, e permitiu que pudessem se dar conta dos movimentos de segregação realizados por eles no âmbito da própria turma, por outro lado, há pontos que restam para serem trabalhados na 
relação com os professores.

Desse modo, ao final da pesquisa/intervenção, os adolescentes demonstram que também gostariam que seus professores fossem os "melhores" e passam a tecer inúmeras críticas à maneira de atuação dos adultos em sala de aula. Os alunos apontam aspectos pertinentes que, sem dúvida, reenviam a impasses contemporâneos relativos à posição do professor de uma maneira mais ampla, incluindo aqui o desrespeito. O cenário descrito pelos alunos aponta para professores que se ocupam de suas questões pessoais em sala de aula e que recuam diante da tarefa da transmissão, ou seja, que estariam desconectados de seu desejo de ensinar. Sabemos que quanto mais conectado com o desejo de ensinar mais é possível transmitir. Os alunos nos fizeram formular uma pergunta que consideramos fundamental para qualquer professor em qualquer escola: como está para cada um a conexão com o desejo de ensinar? A pergunta com relação ao desejo de ensinar foi levada para os professores na Conversação devolutiva.

Ao privilegiar o dizer, a Conversação pode ter um efeito de deflação no mundo das imagens (Santiago, 2015). A Conversação parece incluir o impossível, garantir um lugar para o real, alí onde se tenta a todo custo negar sua existência. Ao dar lugar para o indizível a partir do exercício do dizer, permitindo aos adolescentes falar com consequências, partimos da imagem e de sua função fundamental e formadora do eu para ir além dela, abrindo espaço para a marca pessoal que testemunha a singularidade com a qual cada um se vira diante do impossível de tudo saber. 0 jogo simples de adivinhação revela que somos constituídos pelo Outro mas que nem tudo está dado. Vemos com os jovens que é preciso admitir a falta e se reconciliar com ela (Gallo, 2015).

\section{Da identificação à segregação (e mais além)}

Freud em seu texto Psicologia de grupo e a análise do ego (1921/1996) nos lança o que considera os principais mecanismos presentes nos grupos humanos. De imediato, podemos destacar dois pontos importantes para pensar a vida em sociedade: não há psicologia do indivíduo em oposição à psicologia dos grupos, uma vez que o ser humano se constitui em sua relação com o outro; bem como que o vínculo entre os semelhantes não é dado a priori, mas construído a partir de sentimentos ambivalentes. Neste texto, Freud nos apresenta a identificação como "a mais remota expressão de um laço emocional com outra pessoa" (1921/1996, p.115). Para desenvolver esse conceito, ele parte da família como primeiro grupo onde estamos inseridos. A identificação seria esboçada aqui nos sentimentos, por exemplo, que um menino nutre pelo pai durante o Complexo de Édipo. Esses sentimentos seriam uma mistura entre o interesse pelo pai, a idealização de seus atributos, a vontade de ser como ele, para então tomar o seu lugar inclusive frente à mãe, esta sendo seu objeto de desejo (Freud, 1921/1996).

Assim, para além da relação de objeto (sexual), Freud situa a identificação como uma forma de laço entre as pessoas. Contudo, um laço que contém uma cota de hostilidade em sua origem. "A identificação, na verdade, é ambivalente desde o início; pode tornar-se expressão de ternura 
com tanta facilidade quanto um desejo do afastamento de alguém" (Freud, 1921/1996, p.115). A identificação é tomada como um primeiro tipo de laço, uma tentativa de moldar o eu, de dar-lhe forma. Reencontramos aqui a relação ambivalente do sujeito com sua própria imagem, sua primeira identificação ao espelho, narcísica, com a imagem que passa a lhe representar, mas não todo (Lacan, 1949/1998). Para além da identificação narcísica pensada por Lacan, Freud situa no laço três diferentes origens de identificação: ao pai ideal, modelo que explicaria a configuração dos grupos em sua relação com o líder; a identificação ao objeto de amor, na qual o sujeito se confunde entre o amor e a identificação, ao amar e ser amado pelo líder de um grupo; e a identificação histérica, apoiada no desejo de estar na mesma situação que outra pessoa (Freud, 1921/1996; Ramirez, 2010).

Todas as formas citadas de identificação estão presentes nas relações grupais, que ocorrem quando "um certo número de indivíduos [...] colocaram um só e mesmo objeto no lugar de seu ideal do ego e, consequentemente, se identificaram uns com os outros em seu ego" (Freud, 1921/1996, p.126). Nesse formato de grupo, que Freud denominou primário, percebemos a existência de laços em direção ao líder, e em relação aos pares, a partir de um denominador comum. O líder assume a função de dar unidade ao grupo a partir de um ideal, não necessariamente encarnado em uma pessoa. Ele regula a relação entre os corpos (Santiago \& Faria, 2013). Assim, podemos destacar que a produção de um grupo passa também pelo sentimento de uma homogeneidade, da eleição de um traço identificatório que une, que faz laço. Logo, a agressividade existente na relação constitutiva do sujeito com o outro, e que também se apresenta na ambivalente relação com o líder e com os pares, é redirecionada para fora do grupo. "Trata-se, portanto de uma lógica binária, própria dos bandos, na qual o ideal cria uma fronteira entre o externo e interno demarcando claramente a separação entre o amigo e o inimigo" (Santiago \& Faria, 2013). A partir de um traço eleito no ideal, no líder, os membros de um grupo passam a se identificar entre si, estabelecendo uma relação horizontal, e, para sustentá-la, demarcando sempre sua diferença no exterior do grupo (Ramirez, 2010).

Ramirez (2000), ao abordar a segregação, relembra-nos de sua função na constituição subjetiva, por nos indicar que também nos processos grupais os componentes detestados em nós devem ser negados e atribuídos ao outro. Para se afirmar eu sou eu, deve-se negar eu sou os outros. Destaca, além disso, como a segregação aparece na relação com a própria imagem no espelho, tomada como persecutória pelo sujeito (Ramirez, 2000). Esclarece-nos, ainda, que a segregação é uma tendência dos grupos humanos em sua essência, instaurando a discriminação a todos que não compartilham de seu código. O código seria o Outro lacaniano, os significantes a partir dos quais um grupo se forma, que são compartilhados por ele. Há, portanto, nos grupos artificiais, um Outro que regula o gozo de seus membros, fazendo com que os excessos sejam remetidos para fora, também como prova de pertencimento ao grupo, ao ideal, ao líder. Para me afirmar, preciso negar o outro, essa é a base da relação especular e imaginária, persecutória em 
sua gênese. Ramirez (2000) relembra-nos que a relação do humano com o mundo, inicialmente, passa pela indiferenciação entre o corpo e seu meio, havendo apenas as sensações de prazer e desprazer. A diferença nos é imposta por meio da presença daquele que irá nos auxiliar a regular essas sensações, nos possibilitando alívio, satisfação. Essa primeira diferença comumente é exercida pela mãe, pela oferta da saciedade e do prazer e, ao mesmo tempo, pela privação que esta oferece ao bebê diante de uma saciedade que não pode ser toda, introduzindo as frustrações daí decorrentes. Como vimos, o bebê tende, nesse momento de distinção, a vivenciar as boas sensações como se the pertencessem, colocando a frustração no campo do Outro. 0 reconhecimento da alteridade ocorre marcado por esse componente do mal (Ramirez, 2000).

Na contemporaneidade, a questão da diferença nos é evidenciada por Miller a partir do último ensino de Lacan, ao abordar o conceito de extimidade. Esse êxtimo representa o fora e o dentro ao mesmo tempo, o estranho e o familiar, revelando que o ódio ao Outro, ao modo como o Outro goza é, ao mesmo tempo, o ódio direcionado a este Outro dentro de mim, é ódio ao meu modo de gozo (Miller, 2010[2008] citado por Santiago \& Faria, 2013).

Nessa relação, a violência surge como um não reconhecimento da alteridade, como uma força que visa eliminar a diferença, anular o outro. Em nosso tempo, percebemos que o modelo freudiano de grupos humanos cedeu a novas configurações. O líder, representado pelo pai, já não mais se apresenta como um regulador de gozo à medida que a globalização se alastra. 0 interdito é colocado em questão, e as barreiras tendem a cair. Miller (2011) caracteriza essa época como estruturada pelo não-todo, esclarecendo que não se trata de um não que introduza a falta no todo, mas ao contrário, um conjunto que não se fecha, permanece aberto, infinito. As estruturas totalitárias dão lugar ao ideal do consumo nas sociedades capitalistas, principalmente as ocidentais. Assim, os importantes movimentos políticos e sociais que tiveram início no pós-guerra, questionando o totalitarismo e as arbitrariedades do líder, sempre exceção diante da lei que nos rege, foram abafados por um imperativo ao consumo, no qual demitimos os ideais e assumimos um empuxo ao gozo. Nesse novo mundo, o laço entre os homens encontra-se disperso (Miller, 2011), o modo de viver junto é abalado: "o laço social existe sob a forma de sujeitos desarticulados, dispersos, e que ao mesmo tempo induz a cada um a um dever social e uma exigência subjetiva de invenção" (p.14). Aqui poderíamos ousar interpretar a crescente intolerância como uma tentativa de fronteira frente ao outro na ausência do Outro, no momento em que as fronteiras são abolidas pela globalização, passando por cima dos elementos culturais e discursivos que construíram durante anos a identidade dos povos e dos países.

São muitas as segregações que irrompem em nosso tempo, assim tomadas no plural, se multiplicam e se radicalizam em diversas partes do mundo. Barreiras físicas ou não, invisíveis ou não, para impedir fluxos migratórios, mas também deslocamentos no espaço urbano, entre bairros, entre periferia e regiões privilegiadas, e o próprio fechamento sem dialética de alguns grupos sociais. Antes a segregação provinha do Outro, agora parece se mostrar autorregulada e 
até mesmo reivindicada (Brousse, 2019).

A ascensão da segregação e sua pluralização como produto de uma mutação discursiva, produz sujeitos-objetos, ou seja, reduzidos a números e marcas genéticas, sob o imperativo de uma forma específica de gozar (Brousse, 2019). Trata-se então de uma identificação com o outro que vai se estabelecer não sobre a falta a ser mas sobre o objeto de gozo, produzindo um discurso calcado na dominação dos corpos.

A extensão da segregação se vale da substituição do sujeito dividido pelo sujeito puro da ciência. A gestão dos sujeitos divididos só pode ser operacionalizada a partir do sintoma e exige a linguagem e a fala. Se esses sujeitos são reduzidos a dados cifrados e a uma escrituração, a gestão se faz sem a fala. A segregação é o modo de gestão das massas humanas que permite curto-circuitar a divisão. (Brousse, 2019, p. 157).

Brousse (2019) propõe que, enquanto acreditamos que a civilização padece de uma homogeinização como sua principal marca, o que caracteriza a contemporaneidade é a ramificação da segregação. Ou seja, uma superposição e proliferação de barreiras em todos os graus.

Se o líder, assim como a identificação edipiana, teria uma função apaziguadora da agressividade, contudo, na atualidade, observamos uma intolerância crescente diante das diferenças, paralela à universalização do sujeito pela via da globalização. Quando o consumo pretende apagar as diferenças constitutivas dos grupos, das nações, das comunidades, das classes, elas vão aparecer de outra forma, retornando de maneira ainda mais voraz, não sendo muitas vezes apaziguadas por um líder, mas exaltadas por ele. Podemos perceber esse processo, ao vermos a crescente adesão de adolescentes franceses ao fundamentalismo, ou mesmo nos discursos segregatórios encontrados nas manifestações políticas no Brasil desde 2013, nas quais havia vozes pedindo o retorno do líder ditador ou até mesmo uma intolerância agravada aos nordestinos, por terem votado maciçamente no então presidente do Brasil. Esta intolerância se esboçou inclusive por meio de falas incentivando a separação do nordeste do restante do país. Em tempos do ideal da igualdade, a lógica do consumo, com seu sujeito universal, faz com que esse ideal seja de ordem cada vez mais individual, do direito ao gozo, e não de uma igualdade sociopolítica para driblar as adversidades da civilização, permitindo uma vida na coletividade, uma gestão do comum. A igualdade, quando guiada pelo consumo, visa a um apagamento da diferença e da divisão que nos constitui, acreditando não no sujeito, barrado pela linguagem, constituído a partir de uma perda fundamental e irrecuperável, mas que o movimenta. Esse ideal, pelo contrário, toma o contorno de uma crença no eu, uma apologia ao indivíduo.

Há um mal-estar irredutível, o qual o avanço tecnológico, científico e capitalista, não eliminou. É com esse mal-estar que trabalhamos em nossas pesquisas e dispositivos metodológicos. Como essa força que visa eliminar a diferença produzindo efeitos de segregação 
aparece, por exemplo, nas escolas? Vimos em nossa experiência relatada o quão sufocante as nomeações podem ser, inclusive escavando destinos mortíferos para aqueles que estão alienados a elas. Consentir com o mal-estar, advertidos de sua perenidade, possibilita ao sujeito encontrar sua marca própria, seu jeito de fazer com o sintoma, sem passar pela segregação - pela anulação do outro. Para tanto, torna-se fundamental desconfiar das nomeações, fazendo da demanda maciça, enigma. É desta forma que a psicanálise pode operar junto à escola, auxiliando alunos, professores e corpo diretivo a se responsabilizarem por sua marca pessoal, de maneira a caber no laço a diferença de cada um. Cientes de que não há laço sem ruídos, não há saber sem resto.

\section{Para concluir}

Vimos que para ocupar os lugares do ensino e da aprendizagem, tornando possível alguma transmissão, não nos servimos mais dos rígidos ideais que tanto lutamos para desconstruir. A escola se depara com novas cenas, efeitos dessa desconstrução do mundo dos ideais consistentes, nomeados como mutação da ordem simbólica, ou seja, aquilo que nos orientava socialmente sofreu expressivas mudanças. Verificamos que a digitalização do mundo não fez cessar nossos analógicos problemas na relação com o outro, especialmente entre alunos, em foco nesse artigo.

Os adolescentes nos evidenciam que, se a imersão no mundo virtual ilusoriamente os faria prescindir do Outro para aprender algo, para cerzir algum saber possível, não é sem impasses que se situam diante dos nomes que ainda recebem deste Outro no real da vida escolar e familiar. Se 0 virtual possibilita refazer uma imagem de si mesmo, esta não parece ser suficiente para se proteger contra os nomes que encontram na cidade. Se apreendemos a adolescência como esse furo no saber diante de um corpo que pulsa e que não encontra no mundo dos adultos prescrições exatas para o saber fazer com os enigmas do sexo e da morte, os Outros com os quais esses adolescentes se deparam hoje parecem constantemente embaraçados com essa função, não podendo muitas vezes se situarem como referências para as novas gerações.

Os melhores alunos de repente se tornaram desrespeitosos com os "maus" professores, exigindo-Ihes com o mesmo rigor ao qual eram submetidos colados ao nome do "melhor". Dentro da sala, o desrespeito entre a turma era flagrante, sendo difícil a convivência com a diferença, com aquilo que ultrapassa a posição que lhes foi outorgada. Pela marca do melhor, encontravam uma suposta homogeneidade de alunos que "tiravam cem" e buscavam diferenciar-se, "rebaixando" o colega em diversos sentidos, seja pela calça jeans, seja pelo seu modo de falar, ou modo de ser. Isso se radicalizava na experiência da classe com seus quatro "elementos", que tornavam nítida a pluralidade das singularidades, expressamente negada pela turma.

Vimos como operou o trabalho das Conversações, não no sentido de desvendar o malentendido, mas permitindo que ele pudesse ser ressituado a partir da livre circulação da palavra, e a fala ganhasse aos poucos outra dimensão, além da queixa. Assim, adultos e adolescentes, ao se escutarem, promoveram giros nos nomes e certezas que petrificavam seus atos e que não thes 
davam margem para ultrapassá-los. Um professor pode, sem abrir mão de seu lugar, se servir do digital, não sem a regra, para se aproximar do aluno e capturar seu desejo de saber. Um aluno pode manifestar aos demais a sua marca pessoal, sem para tanto deixar de pertencer àquele grupo. Se inicialmente encontramos frustrados e implicantes, as Conversações permitiram a palavra tocar de outra forma o corpo, esboçando a novidade e a surpresa. 0 inédito que se apresenta é justamente a implicação subjetiva nas cenas das quais fazemos parte, onde não eliminaremos o mal-estar e seus impasses, mas nos responsabilizaremos pelas nossas invenções para lidar com o real e seu impossível, frente aos adolescentes e jovens, frente aos adultos.

Percebemos, ainda, na clínica e na teoria psicanalíticas, novos modos de vivenciar a relação com o outro e com a cidade, na medida em que o excesso de gozo que transborda os corpos, não encontra um Outro regulador, que introduza um véu a ser manejado para possibilitar viver em sociedade. Na época dos semblantes, onde não nos servimos mais do Nome-do-Pai para vivermos juntos, resta-nos alojar esse excesso na invenção possível a cada sujeito, sabendo que nem sempre esta apontará para a vida. É com esse mal-estar que trabalhamos.

Em paralelo, é fundamental ouvir dos professores seus embaraços diante da impossível (Freud, 1925/1996) tarefa de ensinar e destacar sua importante função de apresentar o mundo estabelecido aos mais novos. $O$ ato de ensinar abre o caminho para o mundo da cultura e fornece a base para que a geração seguinte possa assentar suas novidades. Ao sustentarmos o impossível como ponto de partida de (des)encontro, convidamos as escolas para ultrapassar eventuais destinos mortíferos e a sensação de generalizada de impotência diante do que disfunciona. Escutar o sintoma para então operar a partir dele.

\section{Notas:}

1. Por meio de suas metodologias, o NIPSE desenvolve pesquisa / intervenção de orientação psicanalítica em escolas públicas e privadas, espaços educativos e socioeducativos. A perspectiva é a de trabalhar com aqueles que são considerados como alunos-problema, crianças e jovens que não aprendem na idade certa, que não se alfabetizam, que apresentam comportamentos tidos como indesejados, que são considerados agressivos, violentos ou com sexualidade exacerbada. Tomar o sujeito como objeto de conhecimento, marcá-lo por um diagnóstico que oscila entre a patologia e a disfunção, concluindo por um déficit define uma concepção de sintoma oposta àquela que orienta as pesquisas do NIPSE (Santiago, 2005).

2. A metodologia em questão foi proposta por Santiago (2008) para a pesquisa/intervenção no campo da educação de acordo com a experiência do dispositivo da Conversação sugerida por Miller (2003) para os encontros clínicos do Campo Freudiano. A Conversação é composta de um dispositivo simples e exigente que confronta os participantes com as 
consequências de sua fala. A Conversação instaura um espaço de troca que vai além da escuta passiva, trata-se de uma proposta que articula a pesquisa com a aprendizagem por meio da fala. Partimos da proliferação dos significantes no grupo para operar a partir dos mal-entendidos da linguagem (Miranda, Vasconcelos \& Santiago, 2006). A metodologia contempla sete encontros ao todo. Consideramos que a pesquisa/intervenção deve ser sempre pontual e que não se deve permanecer tempo demais em cada instituição, isso nos mantém como um elemento estrangeiro, como um ponto êxtimo, que impulsiona o grupo ao tempo de concluir. $O$ trabalho se inicia por uma Conversação Diagnóstica com a direção e os professores da escola. Trata-se do momento no qual escutamos e interrogamos as nomeações e as queixas trazidas pelos adultos em relação aos jovens. Em seguida, partindo dessas queixas apresentadas pelos adultos, e realizamos com os jovens cinco encontros de Conversação. Ao final dos cinco encontros, é construída junto com o grupo de participantes, uma devolutiva, ou seja, os pontos que eles gostariam que fossem levados como retorno aos adultos. É com base nesses pontos, acordados com o grupo, que é realizado o último encontro com a direção e com os professores para a devolutiva conclusiva do processo. Totalizamos sete encontros: a conversação diagnóstica, os cinco encontros com os jovens e a conversação devolutiva. O número de encontros pode variar dependendo da necessidade de cada grupo.

\section{Referências Bibliográficas}

Albuquerque, B. S. (2019). Do furo à entrada no túnel: reviravolta da linguagem e da sexualidade na adolescência. (Tese de Doutorado). Faculdade de Educação da Universidade Federal de Minas Gerais, Belo Horizonte.

Brousse, M-H. (2019). Segregações versus subversão. In M-H Brousse. Mulheres e discursos. (pp. 155-159). Rio de Janeiro: Contracapa.

Freud, S. (1996). Psicologia de grupo e a análise do ego. In J. Salomão (Trad.) Edição standard brasileira das obras psicológicas completas de Sigmund Freud (Vol. 18, pp. 79-156). Rio de Janeiro: Imago (Trabalho original publicado em 1921).

Freud, S. (1996). Prefácio à Juventude Desorientada de Aichhorn. In J. Salomão (Trad.) Edição standard brasileira das obras psicológicas completas de Sigmund Freud (Vol. 19, pp. 305-308). Rio de Janeiro: Imago (Trabalho original publicado em 1925).

Gallo, H. (2015). O império das imagens. VII Enapol, O Império das Imagens. Recuperado de: http://oimperiodasimagens.com/pt/faq-items/o-imperio-das-imagens-hector-gallo/

Lacadée, P. (2017). O adolescente na escola e a psicanálise. In A. L. Santiago et al. (Org.) Mais além do gênero: o corpo adolescente e seus sintomas. Belo Horizonte: Scriptum. 
Lacan, J. (1998). O estádio do espelho como formador da função do eu. In J. Lacan. Escritos. (pp. 96-103). Rio de Janeiro: Jorge Zahar Editor. (Trabalho original publicado em 1949)

Lacan, J. (1998, dez.). Conferência em Genebra sobre o sintoma. Opção lacaniana - Revista Brasileira Internacional de Psicanálise. São Paulo, v. 23, 6-16. (Conferência proferida em 1975).

Miller, J-A. (2000). A teoria do parceiro. In: E. Monteiro \& V. A. Ribeiro. (Org.) Os circuitos do desejo a vida e na análise. (pp 153-207). Rio de Janeiro: Contra Capa.

Miller, J-A. (2003). Problemas de pareja, cinco modelos. In J-A. Miller. La pareja e el amor: conversaciones clínicas en Barcelona. Barcelona: Eólia.

Miller, J-A. (2011, nov.). Intuições Milanesas II. Opção Lacaniana online nova série. [On-line], ano 2, n.6, 01-21. Recuperado de: http://www.opcaolacaniana.com.br/pdf/numero_5/Intui\%C3\%A7\%C3\%B5es_milanesas.pdf Miller, J-A. (2015). O osso de uma análise + $O$ inconsciente e o corpo falante. Rio de Janeiro: Zahar.

Miranda, M. P., Vasconcelos, R. N. \& Santiago, A. L. B. (2006, nov.). Pesquisa em psicanálise e educação: a conversação como metodologia de pesquisa. In Conversações Livres, Psicanálise, Educação e Transmissão. VI Colóquio do LEPSI, USP, São Paulo. Recuperado de: http://www.proceedings.scielo.br/scielo.php?pid=MSC0000000032006000100060\&script=sci_ arttext

Ramirez, M. E. (2000, ago.). Identidad y segregación. In Revista Poiésis. Medellin, n.1, 01-07. Recuperado de: http://www.funlam.edu.co/revistas/index.php/poiesis/article/view/1112/1010 Ramirez, M. E. (2010). Actualidad de la agresividad en psicoanálisis de Jacques Lacan. Buenos Aires: Grama Ediciones.

Santiago, A. L. (2005). A inibição intelectual da Psicanálise. Rio de Janeiro: Jorge Zahar.

Santiago, A. L. (2008). Conversação de orientação psicanalítica metodologia de pesquisa/intervenção sobre os impasses na educação. In L. Rabello de Castro \& V. Besset. (Orgs.). Pesquisa/intervenção na infância e juventude. (pp. 113-131). Rio de Janeiro: Trapera/FAPERJ.

Santiago, A. L. (2011). Entre a saúde mental e a educação: abordagem clínica e pedagógica de sintomas na escola nomeados por dificuldades de aprendizagem e distúrbios de comportamento. In A. L. Santiago \& R. H. F. Campos (Orgs.) Educação de crianças e jovens na contemporaneidade: pesquisas sobre sintomas na escola e subjetividade. Belo Horizonte: PUC Minas.

Santiago, A. L. (2015). Rumo ao VII ENAPOL O Império da Imagens. VII Enapol, O Império das Imagens. Recuperado de: http://oimperiodasimagens.com.br/pt/faq-items/rumo-ao-viienapol-o-imperio-das-imagens-ana-lydia-santiago/

Santiago, A. L. (2017). Genre et homophobie à l'école: une question pour la condition 
d'adolescent. In A. L. Santiago et al. (Org.) Mais além do gênero: o corpo adolescente e seus sintomas. Belo Horizonte: Scriptum.

Santiago, J. \& Faria, L. F. (2013, mai.). Gangues: os efeitos do abalo do Nome-do-Pai no contexto da violência juvenil. Revista aSEPHallus, vol. VIII, n. 16. Recuperado de: http://www.isepol.com/asephallus/numero_16/artigo_01.html

Citação/Citation: Simões de Albuquerque, B. \& Braun, L. \& Lydia Bezerra Santiago, A. (mai. 2019 a out. 2019). Uma conversação com os melhores alunos: do sintoma como funcionamento ao mais além da segregação. Revista aSEPHallus de Orientação Lacaniana, 14(28), 106-124. Disponível em www.isepol.com/asephallus. Doi: 10.17852/1809-709x.2019v14n28p106-124

Editor do artigo: Tania Coelho dos Santos.

Recebido/Received: 02/08/2019 / 08/02/2019.

Aceito/Accepted: 04/10/2019 / 10/04/2019.

Copyright: (c) 2019 Associação Núcleo Sephora de Pesquisa sobre o moderno e o contemporâneo. Este é um artigo de livre acesso, que permite uso irrestrito, distribuição e reprodução em qualquer meio, desde que o autor e a fonte sejam citados/This is an open-access article, which permites unrestricted use, distribution, and reproduction in any medium, provided the author and source are credited. 